\title{
Clinical, microbiological, and immunological aspects of healthy versus peri-implantitis tissue in full arch reconstruction patients: a prospective cross-sectional study
}

\author{
Javier Ata-Ali ${ }^{1,2^{*}}$, Antonio Juan Flichy-Fernández ${ }^{2}$, Teresa Alegre-Domingo ${ }^{3}$, Fadi Ata-Ali ${ }^{3}$, Jose Palacio ${ }^{4}$
} and Miguel Peñarrocha-Diago ${ }^{2}$

\begin{abstract}
Background: Due to the world-wide increase in treatments involving implant placement, the incidence of peri-implant disease is increasing. Late implant failure is the result of the inability to maintain osseointegration, whose most important cause is peri-implantitis. The aim of this study was to analyze the clinical, microbiological, and immunological aspects in the peri-implant sulcus fluid (PISF) of patients with healthy dental implants and patients with peri-implantitis.

Methods: PISF samples were obtained from 24 peri-implantitis sites and 54 healthy peri-implant sites in this prospective cross-sectional study. The clinical parameters recorded were: modified gingival index (mGl), modified plaque index (mPI) and probing pocket depth (PPD). The periodontopathogenic bacteria Tannerella forsythia, Treponema denticola and Porphyromonas gingivalis were evaluated, together with the total bacterial load (TBL). PISF samples were analyzed for the quantification of Interleukin (IL)-8, IL-1 $\beta, I L-6, I L-10$ and Tumor Necrosis Factor (TNF)-a using flow cytometry (FACS).

Results: The $\mathrm{mGl}$ and PPD scores in the peri-implantitis group were significantly higher than the healthy group $(p<0.001)$. A total of $61.5 \%$ of the patients with peri-implantitis had both arches rehabilitated, compared with $22.7 \%$ of patients with healthy peri-implant tissues; there was no implant with peri-implantitis in cases that received mandibular treatment exclusively $(p<0.05)$. Concentrations of Porphyromonas gingivalis $(p<0.01)$, association with bacteria Porphyromonas gingivalis and Treponema denticola $(p<0.05)$, as well as the TBL $(p<0.05)$ are significantly higher in the peri-implantitis group. IL-1 $(p<0.01)$, IL-6 $(p<0.01)$, IL-10 $(p<0.05)$ and TNF-a $(p<0.01)$ are significantly higher at the sites with peri-implantitis compared to healthy peri-implant tissue, while IL-8 did not increase significantly.

Conclusion: The results of the present study involving a limited patient sample suggest that the peri-implant microbiota and which dental arch was rehabilitated involved could contribute to bone loss in peri-implantitis. A significant relationship is observed between the concentration of cytokines (interleukins $1 \beta, 6$ and 10 and TNF-a) and the inflammatory response in peri-implantitis tissue.
\end{abstract}

Keywords: Peri-implantitis, Cytokine, Review, Periodontal pathogens, Peri-implant diseases, Dental implant, Peri-implant sulcus fluid (PISF)

\footnotetext{
* Correspondence: javiataali@hotmail.com

${ }^{1}$ Public Dental Health Service, Arnau de Vilanova Hospital, San Clemente

Street 12, 46015 Valencia, Spain

${ }^{2}$ Oral Surgery and Implantology, Valencia University Medical and Dental

School, Valencia, Spain

Full list of author information is available at the end of the article
} 


\section{Background}

The restoration of missing teeth by means of dental implants has now become a routine treatment in common use [1]. Various longitudinal studies have shown the high survival rates of implants in functional use, which range between $90 \%$ and $95 \%$ over a follow-up period of up to 20 years [2-4]. Peri-implant disease infection etiology has been described in detail in the literature for both mucositis [5-8] and peri-implantitis [9-12]. Late implant failure is the result of the inability to maintain osseointegration, whose most important cause is peri-implantitis [1].

Using the checkerboard DNA-DNA hybridization method, Socransky et al. [13] identified a consortium of the bacterial species Tannerella forsythia (T. forsythia), Treponema denticola ( $T$. denticola) and Porphyromonas gingivalis ( $P$. gingivalis) as having the highest association with periodontal disease severity. The authors named this microbial consortium "red complex". Evaluation of the literature has shown the microbiota associated to peri-implantitis to be more complex than that found under healthy peri-implant conditions - the main flora consisting of anaerobic gram-negative bacteria [14]. A high degree of association between this red complex and the appearance of peri-implantitis has been observed $[9-12,14]$. However, in healthy peri-implant sulci, oral streptococci constitute the predominant bacterial flora [15].

Although different cytokines have been evaluated [16-18], the cytokine concentrations that differentiate between healthy and stable sites and the onset of a pathological periodontal and peri-implant process are not known [19]. In the periodontium, individual differences in inflammatory and immunological responses to bacterial infection may influence the host's susceptibility to disease [20]. The cascade of inflammatory mediators of the host in response to bacterial infection, which can result in destruction of connective tissue and bone, is determined by genetic factors [21].

The aim of this study was to study the clinical characteristics of peri-implantitis as established by the modified plaque index, modified gingival index and probe depth, examines the microbial and host response Interleukin (IL)-8, IL-1 $\beta$, IL-6, IL-10 and Tumor Necrosis Factor (TNF)- $\alpha$ characteristics in dental implants with periimplantitis, and establishes comparisons with healthy dental implants.

\section{Methods}

\section{Study population}

This is a prospective cross-sectional study of clinical, microbiological and immunological markers of 24 periimplantitis and 54 healthy peri-implant sites. Sixty-six patients were treated at the Department of Oral Surgery and Implantology at Valencia University Medical and Dental School (Valencia, Spain). All patients presented at least one completely edentulous dental arch, which were rehabilitated with dental implants (Figure 1). All patients were seen by a single examiner (JAA). The study was conducted in accordance with the Helsinki Declaration and the protocol was approved by the institutional review board of the University of Valencia; patients gave their informed consent to participate in the study in writing.

We excluded those patients who had received any kind of local or systemic decontamination treatment of the oral cavity in the previous three months (such as antibiotics or rinses), or periodontal treatment in the previous six months. Patients with uncontrolled periodontal disease (assessed by a specialist in periodontics) were also excluded, in the same way as individuals presenting implants with exposure of the rough surface, patients with systemic diseases (e.g., HIV infection or leukemia) or who were in receipt of drugs capable of altering gingival health in some way, or pregnant women and nursing mothers (Figure 1).

The study population consisted of 35 individuals (22 patients with healthy implants and 13 with periimplantitis). Seventy-eight dental implants were evaluated during the study (24 with peri-implantitis and 54 healthy peri-implant sites). Phibo ${ }^{\circ}$ treatment surface Avantblast (TSA) implants (Phibo Dental Solutions, Sentmenat, Barcelona, Spain) had been implanted in the patient sample, and all implants had been in functional use for at least 24 months. The data collected was analyzed, relating them to age, sex, smoking, oral hygiene, which arch had been rehabilitated and the type of prosthesis (Table 1).

\section{Implant inclusion criteria}

The patients were divided into two groups according to whether or not they presented peri-implantitis. Periimplantitis was defined according to Schwarz et al. [22]: implant with a probing depth $\geq 4 \mathrm{~mm}$ and signs of acute peri-implantitis (loss of supporting bone as estimated on radiographs, bleeding on probing or suppuration) and no implant mobility. The inclusion criteria in the group of patients with healthy dental implants were: probing pocket depth $(\mathrm{PPD})<4 \mathrm{~mm}[17,23,24]$, absence of clinical signs of inflammation of the peri-implant mucosa, and without radiographic bone loss. If one of the implants was healthy but another showed signs of peri-implantitis, the patient was classified as having the disease.

The implant with the deepest peri-implant pocket was selected for collection of the microbiological samples and for determining interleukins, selecting one implant from each rehabilitated quadrant. When there were two or more implants with the same probe depth, the most anteriorly positioned implant was selected. 


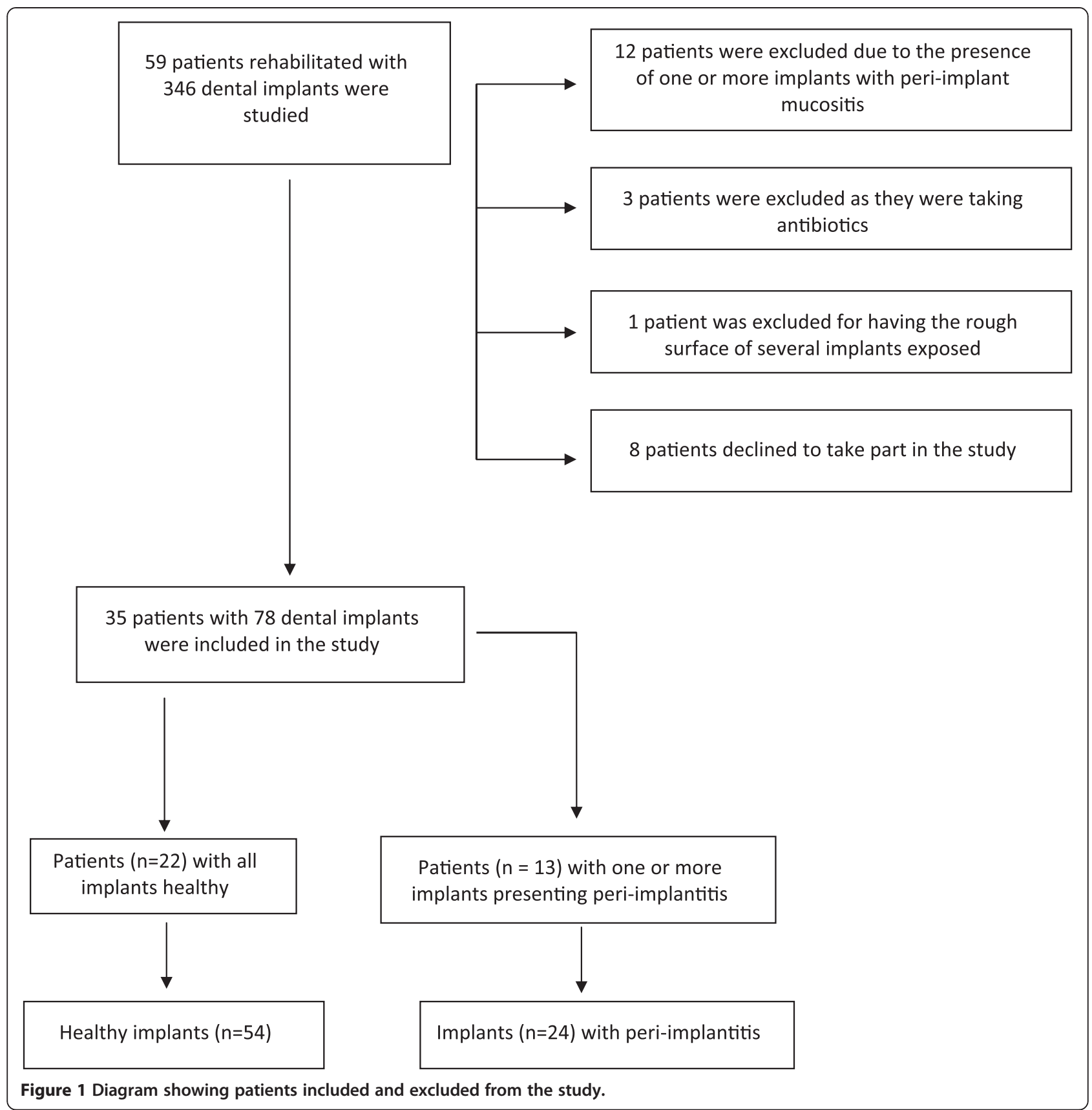

\section{Clinical examination}

We examined all the implants in each patient, recording the implant data per rehabilitated quadrant in each subject (registering two or four implants according to whether the upper maxilla, the mandible, or both were rehabilitated). The modified gingival index (mGI) and the modified plaque index ( $\mathrm{mPI}$ ) were determined for each implant according to methods described by Mombelli et al. [25]. The peri-implant probing pocket depth (PPD) was measured with a probe calibrated to $0.25 \mathrm{Nw}$ (Click Probe, Kerr, USA). Specifically, PPD was measured at the mesiobuccal, mediobuccal, distobuccal, mesiolingual, mediolingual and distolingual points of each implant, and the mean PPD was calculated for each implant [26].

\section{Radiographic evaluation}

Marginal bone loss was measured from the intraoral Xray studies, using the $\mathrm{XMind}^{\ominus}$ intraoral system (Groupe Satelec-Pierre Rolland, Bordeaux, France) and the RVG ${ }^{\circ}$ intraoral digital receptor (Kodak Dental System, Atlanta, GA, USA). The $\mathrm{XCP}^{\oplus} \mathrm{X}$-ray positioning device (Dentsply, Des Plaines, IL, USA) was used to reproduce the angle of the X-rays in later reviews. In order to position the $\mathrm{XCP}^{\circ}$ correctly, the guide bar was placed parallel to the direction 
Table 1 Demographic and clinical description of the study population

\begin{tabular}{|c|c|c|c|}
\hline & Healthy & Peri-implantitis & $\begin{array}{l}\text { Differences } \\
\text { per group }\end{array}$ \\
\hline Age (mean \pm s.d.) & $63.6 \pm 10.4$ & $52 \pm 7.7$ & ** \\
\hline Gender (\% females) Number of patients Number of implants & 59.12254 & 53.81324 & n.s. \\
\hline Smoking habit Non-smokers (\%) & 100.0 & 38.5 & ** \\
\hline Smokers (\%) & 0.0 & 61.5 & \\
\hline Oral hygiene Never (\%) & 0 & 7.7 & n.s. \\
\hline 1-2 times/day (\%) & 63.6 & 46.2 & \\
\hline 3 times/day (\%) & 36.4 & 46.2 & \\
\hline Rehabilitated arch Upper (\%) & 31.8 & 38.5 & * \\
\hline Lower (\%) & 45.5 & 0 & \\
\hline Both (\%) & 22.7 & 61.5 & \\
\hline Prosthesis ${ }^{1}$ Fixed (\%) & 31.8 & 38.5 & n.s. \\
\hline OD Locator ${ }^{\circledast}(\%)$ & 45.5 & 7.7 & * \\
\hline OD Bar (\%) & 9.1 & 38.5 & * \\
\hline Fixed and OD Locator (\%) & 4.5 & 0 & \\
\hline OD Locator and OD Bar (\%) & 4.5 & 7.7 & \\
\hline OD Bar and hybrid (\%) & 4.5 & 0.0 & \\
\hline Hybrid (\%) & 0.0 & 7.7 & \\
\hline
\end{tabular}

Chi-squared test for evaluating differences in gender and type of prosthesis between groups.

Mann-Whitney $U$-test for evaluating differences in smoking, brushing and arch between groups.

Student $t$-test for evaluating age differences between groups.

Note: Only differences in the proportion of the three most frequent types of prostheses are evaluated.

n.s. $=$ nonsignificant

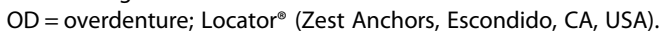

s.d. = standard deviation

${ }^{*} \mathrm{p}<0.05 ;{ }^{* *} \mathrm{p}<0.01$.

of the X-ray beam, perpendicular to the digital receptor. According to the VII European Workshop in Periodontology, to establish the baseline, a radiograph should be obtained to determine alveolar bone levels after physiological remodeling, and peri-implant probing assessments should not be performed before this has taken place as it is assumed that bone loss occurring after initial remodeling is mainly due to bacterial infection [27].

\section{PISF sampling}

Peri-implant sulcus fluid (PISF) was collected from each implant after the presence or absence of plaque ( $\mathrm{MPI}$ ) had been assessed and before registering any other clinical parameters [26]. After calibrating the Periotron ${ }^{\oplus}$ 8000 (Proflow Incorporated. New York, USA), the PISF sample was collected with sterile paper strips (Periopaper Strip ${ }^{\oplus}$ Proflow Incorporated. New York, USA).

The technique used was as follows: a) drying the mouth with aspiration; b) isolation of the zone with cotton rolls; c) gentle drying of the zone; d) sulcus fluid sampling by placing the sterile paper strips in the sulcus between the implant and gums, keeping this position for 30 seconds; e) placement between the sensors of the
Periotron $^{\star} 8000$, to record the amount of PISF obtained in Periotron units previously calibrated following the manufacturer's indications.

PISF was absorbed by each strip. Each sample was diluted in an Eppendorf tube with $200 \mu \mathrm{L}$ of $50 \mathrm{mM}$ phosphate buffer, $\mathrm{pH} 7.2$, together with a pool of protease inhibitors (Roche Diagnostics $\mathrm{GmbH}$, Mannheim, Germany) and $0.1 \mathrm{mM}$ phenyl sulfonyl fluorate, and incubated for two hours. The samples were centrifuged at $1000 \mathrm{~g}$ for five minutes, and the supernatant was stored at $-80^{\circ} \mathrm{C}$ until used.

\section{Cytokine assay}

IL-1 $\beta, 6,8,10$ and TNF- $\alpha$ cytokines were evaluated in the supernatants stored at $-80^{\circ} \mathrm{C}$. The evaluation was performed by using the Human Inflammation Cytometric Bead Array (CBA) system (Becton Dickinson, BD Biosciences, San Diego, CA, USA) and FACS analysis (Becton Dickinson, BD Biosciences, San Diego, CA, USA). The samples and positive controls (standard curve) were processed according to the manufacturer's instructions, and the values for cytokines were calculated and reported as $\mathrm{pg} / \mathrm{ml}$. Data were acquired with a FACS calibur flow cytometer (Becton Dickinson, Franklin Lakes, NJ, USA). 


\section{Microbiological sampling}

Supragingival plaque was removed from the implant with the deepest peri-implant pocket in each quadrant using a curette or cotton roll, without penetrating the gingival sulcus. Cotton rolls were used for relative isolation. The sampling site was dried with an air pistol. Sterile paper tips (Johnson \& Johnson, Medical Inc., Arlington, TX, USA) were inserted in the peri-implant sulcus for 10 seconds. The paper tips were then thoroughly impregnated in a solution of guanidine thiocyanate $4 \mathrm{M}$ and 2-mercaptoethanol contained in a tube. For microbiological analysis, the samples were sent to IAI, Inc., where analyses were made of $T$. forsythia, $P$. gingivalis, T. denticola and the total bacterial load (TBL) using the IAI-PadoTest $4.5^{\circ}$ (IAI Inc., IAI Institute, Zuchwill, Switzerland), a method used by other researchers [28-30]. To this effect, the samples were mounted in nylon membranes and hybridized with specific P32 probes directed against the sRNA ribosomal subunit of the three above mentioned periodontal bacterial species.

\section{Statistical analysis}

The SPSS version 15.0 statistical package for Microsoft Windows (SPSS Inc., Chicago, IL, USA) was used for statistical analysis. Tables 1 and 2 show the statistical tests used for each measure. Statistical significance was considered for $\mathrm{p}<0.05$. The statistical power reached by the Mann-Whitney $U$-test (used in comparing the 24 implants with peri-implantitis versus the 54 without

Table 2 Clinical characteristics of the implants with healthy peri-implant gingiva and with peri-implantitis

\begin{tabular}{llll}
\hline & Healthy & Peri-implantitis & $\begin{array}{l}\text { Differences } \\
\text { per group }\end{array}$ \\
\hline Mean PPD in mm & $2.72 \pm 0.59$ & $5.15 \pm 0.68$ & $*$ \\
$\mathrm{mPI}$ & $0.96 \pm 1.03$ & $1.25 \pm 1.15$ & n.s \\
$0(\%)$ & 46.3 & 37.7 & \\
$1(\%)$ & 18.5 & 16.7 & \\
$2(\%)$ & 27.8 & 29.2 & \\
$3(\%)$ & 7.4 & 16.7 & \\
mGl & $0.63 \pm 0.92$ & $2.71 \pm 0.46$ & \\
$0(\%)$ & 63.0 & 0 & \\
$1(\%)$ & 14.8 & 0 & n.s. \\
$2(\%)$ & 18.5 & 29.2 & \\
$3(\%)$ & 3.7 & 70.8 & \\
PISF & $91.7 \pm 50.3$ & $83.9 \pm 43.1$ & \\
\hline
\end{tabular}

Mean \pm s.d. or $\%$, as indicated.

*p $<0.001$.

Mann-Whitney $U$-test for evaluating differences in PPD, $\mathrm{mPI}$ and $\mathrm{mGI}$ between groups.

Student $t$-test for evaluating differences in PISF between groups.

n.s. = nonsignificant.

$\mathrm{PPD}=$ probe pocket depth; $\mathrm{mPI}=$ modified plaque index; $\mathrm{mGI}=$ modified

gingival index; PISF = peri-implant sulcus fluid. peri-implantitis) in the bacterial load analysis in the sample of 78 implants was 0.88 . A detected effect size of 0.8 was assumed, with a $95 \%$ confidence level $(\alpha=0.05)$.

\section{Results}

Table 1 reports mean patient age $(\mathrm{p}<0.01)$, gender, smoking habits $(\mathrm{p}<0.01)$, oral hygiene, which arch was rehabilitated $(\mathrm{p}<0.05)$ and prosthetic type $(\mathrm{p}<0.05)$ for the two study groups. When prosthetic type was registered, Locator supporting an overdenture was the most frequent in the patient group with healthy peri-implant sites, while overdentures on bars were the most frequent in implants with peri-implantitis. A total of $61.5 \%$ of the patients with periimplantitis had both arches rehabilitated, compared with $22.7 \%$ of patients with healthy peri-implant tissues; there was no implant with peri-implantitis in cases that received mandibular treatment exclusively.

The mean values of clinical parameters for all implants (with or without peri-implantitis) are presented in Table 2 . There were no statistically significant differences in the percentage of sites at which plaque was found between the groups. mGI scores were significantly higher around implants with peri-implantitis than around healthy implants $(\mathrm{p}<0.001)$. The recorded mean PPDs in the peri-implantitis group and the healthy group were $5.15 \pm 0.68$ and $2.72 \pm 0.59$, respectively, this being a statistically significant difference $(\mathrm{p}<0.001)$ (Figure 2$)$. On examining the PISF volumes, no significant differences were observed between the two groups.

The analysis of putative periodontal pathogens of the red complex (T. forsythia, P. gingivalis, T. denticola) and total bacterial load (TBL) are summarized in Table 3. Subgingival microbiota was composed of a greater number of periodontal pathogens in patients with peri-implantitis, showing significant difference in counts of $P$. gingivalis $(\mathrm{p}<0.01)$, in $P$. gingivalis and $T$. denticola association $(\mathrm{p}<0.05)$, as well as TBL $(\mathrm{p}<0.05)$.

The peri-implantitis group showed a significantly greater level of IL- 6 than the healthy group $(0.96 \pm 0.64$ and $0.53 \pm 0.63$ respectively, $\mathrm{p}<0.01) ; \mathrm{IL}-1 \beta(58.5 \pm 84.8$ and $21.2 \pm 24.2$ respectively, $\mathrm{p}<0.01)$; IL- $10(0.91 \pm 0.90$ and $0.45 \pm 0.87$ respectively, $\mathrm{p}<0.05)$; TNF- $\alpha(1.08 \pm$ 1.49 and $0.25 \pm 0.56$ respectively, $\mathrm{p}<0.01$ ) (Figures 3 and 4). Although IL-8 increased in the peri-implantitis group, there was no statistically significant difference in comparison with the healthy implant group. The IL-1 $\beta /$ IL-10 ratio was found to be $9.9 \pm 11.9$ for the healthy group and $37.2 \pm 44.4$ for the peri-implantitis group $(\mathrm{p}=0.006)$.

\section{Discussion}

Due to the world-wide increase in treatments involving implant placement, the incidence of peri-implant disease is increasing. Initial screening of peri-implant tissues will 


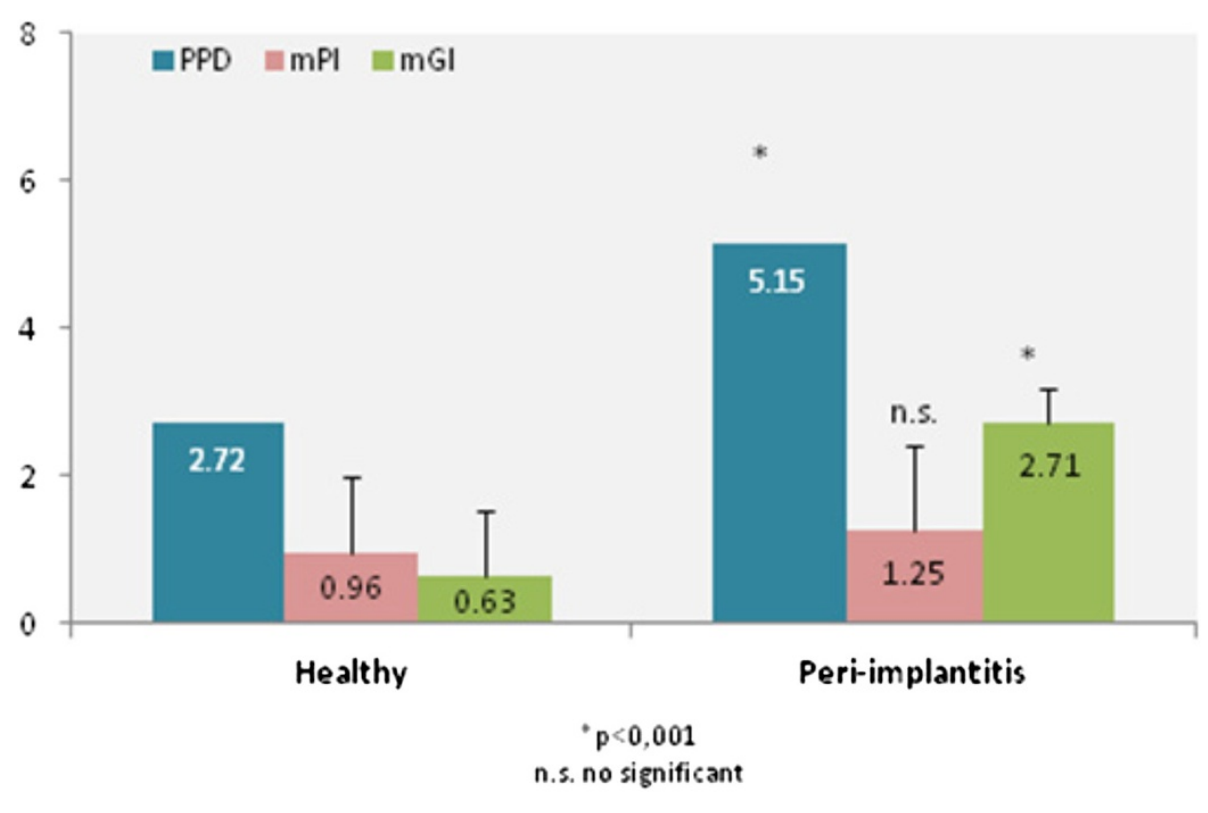

Figure 2 The $\mathrm{mGl}$ and PPD values for the peri-implantitis group were significantly higher than in the healthy group.

consist of an evaluation of peri-implant pocket probing depth and the degree of bleeding on probing [31]. When increased bacterial plaque and bleeding in response to probing affects over $30 \%$ of the dental implants, this situation is related to a high risk of mucositis and periimplantitis [32]. A study [33] involving 34 patients with 77 dental implants (comprising 23 mucositis and 54 healthy periimplant sites) concluded that bacterial plaque induces an inflammatory response that can lead to the development of peri-implant mucositis. A recent systematic review [34] highlights the lack of uniform treatment and the need to establish additional research to fully provide effective treatments for this common condition, which is the first step to prevention periimplantitis. These data are consistent with those published by Shibli et al. [11], which found patients with peri-implantitis to have increments in all the evaluated clinical parameters, except the percentage of locations with bacterial plaque. $\mathrm{mGI}$ score and PPD are parameters that must be evaluated for the diagnosis of peri-implant disease $[27,28,32]$. Accordingly, the present study found that both $\mathrm{mGI}$ and PPD were significantly higher in the implants with peri-implantitis $(\mathrm{p}<0.001)$.

Most studies regarding risk factors for peri-implant disease have concluded that smoking is clearly involved [35-40]. This is also supported by the present study, in which a significant relationship was found between smoking and the presence of peri-implantitis. However, such data should be viewed with caution, since the group with healthy implants consisted of non-smokers; consequently, smoking could not influence the clinical, microbiological and immunological parameters studied.

Patients with peri-implantitis were significantly younger on average than patients with healthy peri-implant tissues, a finding that differs from other studies in which older patients showed higher rates of peri-implantitis [41]. In this population, when prosthetic type was studied, it was found that overdentures supported by Locator ${ }^{\circ}$ were more frequent among patients with healthy periimplant tissues, while overdentures on bars were more frequent on implants with peri-implantitis. In a study by Marrone et al. [41] more cases of peri-implantitis

Table 3 Detection frequencies of target bacteria in subgingival peri-implant sites for each group

\begin{tabular}{lllllllll}
\hline & T. forsythia (Tf) & P. gingivalis (Pg) & T. denticola (Td) & TBL & Tf + Pg & Tf + Td & Pg + Td & Red complex \\
\hline Healthy & $12(22.2 \%)$ & $6(11.1 \%)$ & $9(16.7 \%)$ & $52(96.3 \%)$ & $6(11.1 \%)$ & $6(11.1 \%)$ & $6(11.1 \%)$ & $6(11.1 \%)$ \\
Peri-implantitis & $8(33.3 \%)$ & $9(37.5 \%)$ & $8(33.3 \%)$ & $24(100 \%)$ & $6(25 \%)$ & $6(25 \%)$ & $8(33 \%)$ & $6(25 \%)$ \\
Differences per group & n.s. & $* *$ & n.s. & n.s. & n.s. & n.s. & $*$ & n.s.
\end{tabular}

Chi-squared test for evaluating differences in bacterial presence between groups.

n.s. $=$ nonsignificant.

${ }^{*} p<0.05 ;{ }^{* *} p<0.01$.

Tf: Tannerella forsythia (T. forsythia); Pg: Porphyromonas gingivalis (P. gingivalis); Td: Treponema denticola (T. denticola).

Red Complex $=\mathrm{Tf}+\mathrm{Pg}+\mathrm{Td}$.

$\mathrm{TBL}=$ Total Bacterial Load. 


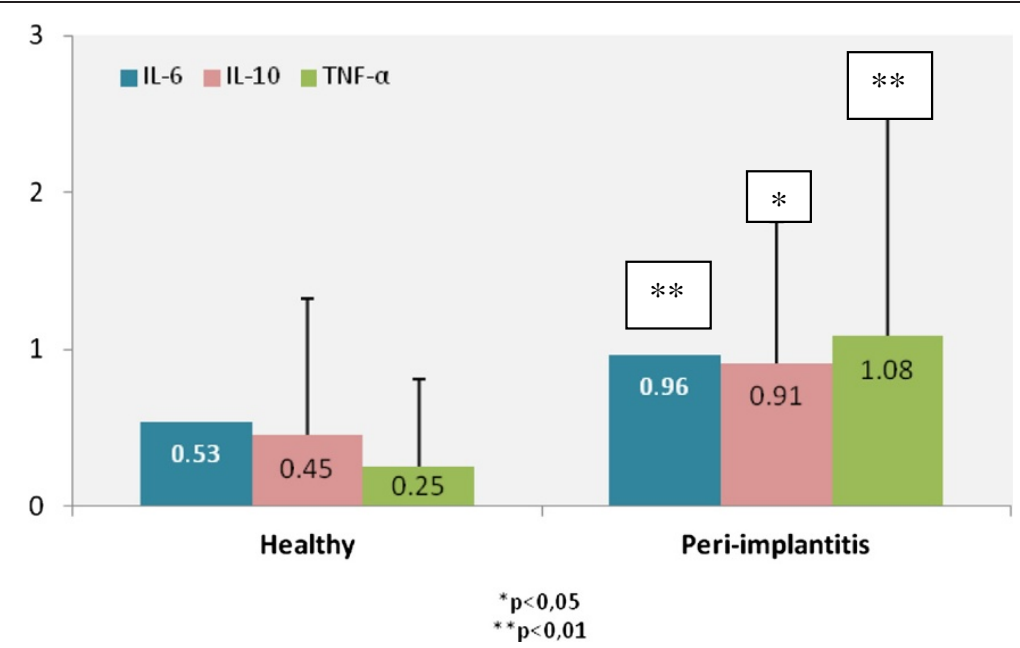

Figure 3 Differences in IL-6 ( $p<0.01)$, IL-10 $(p<0.05)$ and TNF- $a(p<0.01)$ in patients with peri-implantitis and in patients with healthy peri-implant tissues $(\mathrm{pg} / \mathrm{ml})$.

were found in patients wearing overdentures than among patients rehabilitated with fixed prostheses, which agrees with the present results. A total of $61.5 \%$ of the patients with peri-implantitis had both arches rehabilitated, compared with only $22.7 \%$ of patients with healthy periimplant tissues, and there were no cases of implants with peri-implantitis who had undergone rehabilitation of the mandible exclusively.

$P$. gingivalis was detected in the half of gingivitis patients and in more than $80 \%$ of the periodontitis patientsderived samples [42]. High counts of T. forsythia, P. gingivalis and $T$. denticola have been observed in implants with peri-implantitis [9-12]. For the first time, a study demonstrated that the red complex periodontal bacterium Pg produces a concentration of Hydrogen sulfide capable of up-regulating IL-8 expression induced in gingival and oral epithelial cells, revealing a possible mechanism that may promote the inflammation in periodontal disease [43]. In the present study there was a significant relation between peri-implantitis and $P$. gingivalis, association with $P$. gingivalis and T. denticola, and total bacterial load. Other studies [14,44-47] found these bacteria in patients with healthy peri-implant tissue, which was similar to the present sample of healthy peri-implant patients, in which red complex was found at $11.1 \%$ of healthy periimplant sites, while red complex was found at $25 \%$ of implants with peri-implantitis. In a study by Nowzari et al. [23] it was found that $16.7 \%$ of healthy periimplant tissues showed presence of $P$. gingivalis, and $25 \%$ T. forsythia, results that are similar to this study.

One of the options for diagnosing peri-implant disease is peri-implant sulcus fluid (PISF) analysis, which offers

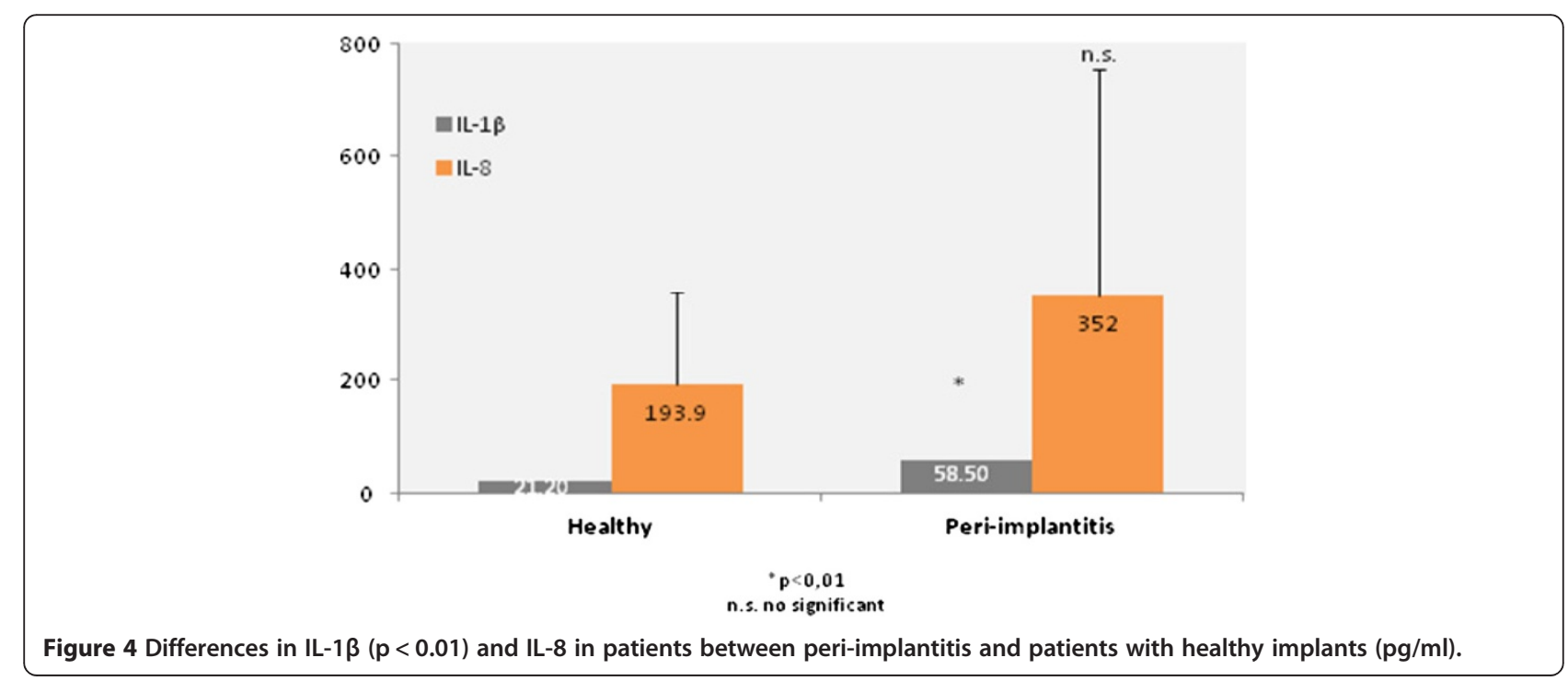


a non-invasive means of studying the host response to peri-implant disease, and may provide an early indication of those patients at risk of developing active disease [16]. In the present study, PISF volume was greater in the healthy implants $(91.7 \pm 50.3)$ than in the peri-implantitis group $(83.9 \pm 43.1)$, though the difference was not statistically significant.

Many studies have examined the presence of cytokines in patients with periodontitis [48-50]. Due to the similarity between periodontitis and peri-implantitis, many inflammatory markers have been evaluated for monitoring peri-implant health and can indicate the presence of either disease [51-53]. Bacterial products from periodontal pathogens stimulate the production of inflammatory mediators secreted in PISF, which cause the destruction of the peri-implant tissues [17]. Certain cytokines have been proposed as potentially valid diagnostic or prognostic markers of periodontal or peri-implant tissue destruction [16]. An increase in interleukin levels is observed in patients with peri-implant disease, though there is controversy over the effect of interleukins in crevicular fluid and peri-implantitis in relation to implant failure or the development of periimplant disease [54]. The IL-10 is an anti-inflammatory cytokine, produced by T-helper 2 cells (Th2), macrophages and B cells, which inhibits synthesis of pro-inflammatory cytokines such as IL-1, IL-2, IL-6, IL-8, TNF-a and IFN-g (interferon gamma) [55]. On the other hand, IL10 acts as a B cell stimulator, enhancing B cell proliferation and differentiation [56]. These facts suggest that IL10 can play important roles in the regulation of celular and humoral immune responses [57]. As regards IL-10, Liskmann et al. (18) reported a higher concentration of IL-10 in patients with peri-implantitis. In contrast, Duarte et al. [58] observed no differences between healthy subjects and patients with disease. Some studies have previously shown interleukin-1ß (IL-1ß) in PISF to be elevated in cases of peri-implantitis $[52,59,60]$. TNF$\alpha$, a cytokine with some functions similar to those of IL-1 $\beta$, has been detected at sites affected by periodontitis [61] TNF- $\alpha$ and IL-1 $\beta$ act synergistically to initiate the cascade of inflammatory mediators [62]. IL-6 has proinflammatory effects and is responsible for the collagen resorption of gingival tissues [63], while IL-10 is an inhibitor of inflammation [64]. IL-8 acts as a potent chemoattractant for neutrophils in gingival tissues [65]. In this study, it was found that IL- $1 \beta(\mathrm{p}<0.01)$, IL-6 $(\mathrm{p}<0.01)$, IL-10 $(\mathrm{p}<0.05)$ and TNF- $\alpha(\mathrm{p}<0.01)$ were significantly increased at the sites with peri-implantitis, while IL-8 was not.

The main component of soft and hard tissue destruction associated with periodontal disease is believed to be the result of activation of the host immunoinflammatory response to bacterial challenge [66]. IL-1 and IL-6 have both been found to be significantly elevated at diseased periodontal sites compared with healthy or inactive sites [67]. IL-1 has also been positively correlated with increased probe depth and attachment loss [68]. Other clinical data indicate that IL-6 levels are higher in refractory periodontitis, and increased granulocyte chemotactic factor (GCF) levels correlate to gram-negative fimbriae [69]. Based upon the increased expression of IL-1 and IL-6 in inflamed gingiva and high levels of GCF in periodontitis patients, several studies have suggested that an increased production of these cytokines may play an important role in periodontal tissue destruction [48].

\section{Conclusions}

An analysis has been made of the clinical, microbiological and host response aspects in implants with peri-implantitis. The results of the present study involving a limited patient sample suggest that the peri-implant microbiota and which dental arch was rehabilitated involved could contribute to bone loss in peri-implantitis. A significant relationship is observed between the concentration of cytokines (interleukins $1 \beta, 6$ and 10 and TNF- $\alpha$ ) and the inflammatory response in peri-implantitis tissue.

\section{Abbreviations \\ T. forsythia: Tannerella forsythia; P. gingivalis: Porphyromonas gingivalis; T. denticola: Treponema denticola; TNF-a: Tumor necrosis factor-a; IL: Interleukin; FACS: Flow cytometry; mGl: Modified gingival index; mPI: Modified plaque index; PPD: Probing pocket depth; TBL: Total bacterial load; TSA: Treatment surface avantblast.}

\section{Competing interests}

The authors declare that they have no competing interests.

\section{Authors' contributions}

All authors contributed extensively to the work presented in this paper. JAA and AJF provided the idea for the project, reviewed the paper and contributed to the writing. JAA, AJF, TAD and FAA recruited the participants, collected the data, and compiled all medical records. JRP analysis peri-implant sulcus fluid samples for the quantification of Interleukins. MPD was responsible for the study design, interpretation of the data together with JAA and FAA, implemented the literature search and final approval of the article. All authors approved the manuscript prior to submission.

\section{Acknowledgements}

The authors would like to thank the patients involved in this study.

\section{Author details}

'Public Dental Health Service, Arnau de Vilanova Hospital, San Clemente Street 12, 46015 Valencia, Spain. ${ }^{2}$ Oral Surgery and Implantology, Valencia University Medical and Dental School, Valencia, Spain. ${ }^{3}$ Valencia University Medical and Dental School, Valencia, Spain. ${ }^{4}$ Immunology Unit, Institute of Biotechnology and Biomedicine, University of Barcelona, Barcelona, Spain.

Received: 11 November 2014 Accepted: 25 March 2015

Published online: 01 April 2015

\section{References}

1. Charalampakis G, Leonhardt Å, Rabe P, Dahlén G. Clinical and microbiological characteristics of peri-implantitis cases: a retrospective multicentre study. Clin Oral Implants Res. 2012;23:1045-54.

2. Lekholm U, Gröndahl K, Jemt T. Outcome of oral implant treatment in partially edentulous jaws followed 20 years in clinical function. Clin Implant Dent Relat Res. 2006;8:178-86. 
3. Astrand P, Ahlqvist J, Gunne J, Nilson H. Implant treatment of patients with edentulous jaws: a 20-year follow-up. Clin Implant Dent Relat Res. 2008;10:207-17.

4. Kim TS, Kang NW, Lee SB, Eickholz P, Pretzl B, Kim CK. Differences in subgingival microflora of Korean and German periodontal patients. Arch Oral Biol. 2009;54:223-9.

5. Renvert S, Roos-Jansåker AM, Lindahl C, Renvert H, Rutger PG. Infection at titanium implants with or without a clinical diagnosis of inflammation. Clin Oral Implants Res. 2007;18:509-16.

6. Ata-Ali J, Flichy-Fernández AJ, Alegre-Domingo T, Candel-Marti ME, Peñarrocha D, Balaguer-Martinez JF, et al. Analysis of the peri-implant microbiota in 90 dental implants and its relationship to crevicular fluid volume. Med Oral Patol Oral Cir Bucal. 2011;16:e944-7.

7. Lang NP, Bosshardt DD, Lulic M. Do mucositis lesions around implants differ from gingivitis lesions around teeth? J Clin Periodontol. 2011;11:182-7.

8. Hallström H, Persson GR, Lindgren S, Olofsson M, Renvert S. Systemic antibiotics and debridement of peri-implant mucositis. A randomized clinical trial. J Clin Periodontol. 2012;39:574-81.

9. Hultin M, Gustafsson A, Hallström H, Johansson LA, Ekfeldt A, Klinge B. Microbiological findings and host response in patients with peri-implantitis. Clin Oral Implants Res. 2002;13:349-58.

10. Botero JE, González AM, Mercado RA, Olave G, Contreras A. Subgingival microbiota in peri-implant mucosa lesions and adjacent teeth in partially edentulous patients. J Periodontol. 2005;76:1490-5.

11. Shibli JA, Melo L, Ferrari DS, Figueiredo LC, Faveri M, Feres M. Composition of supra- and subgingival biofilm of subjects with healthy and diseased implants. Clin Oral Implants Res. 2008;19:975-82.

12. Persson GR, Samuelsson E, Lindahl C, Renvert S. Mechanical non-surgical treatment of peri-implantitis: a single-blinded randomized longitudinal clinical study. II Microbiological Results J Clin Periodontol. 2010;37:563-73.

13. Socransky SS, Haffajee AD, Cugini MA, Smith C, Kent Jr RL. Microbial complexes in subgingival plaque. J Clin Periodontol. 1998;25:134-44.

14. Ata-Ali J, Candel-Marti ME, Flichy-Fernández AJ, Peñarrocha-Oltra D, Balaguer-Martinez JF, Peñarrocha DM. Peri-implantitis: associated microbiota and treatment. Med Oral Patol Oral Cir Bucal. 2011;16:e937-43.

15. Kocar M, Seme K, Hren NI. Characterization of the normal bacterial flora in periimplant sulci of partially and completely edentulous patients. Int J Oral Maxillofac Implants. 2010;25:690-8.

16. Petković AB, Matić SM, Stamatović NV, Vojvodić DV, Todorović TM, Lazić ZR, et al. Proinflammatory cytokines (IL-1 beta and TNF-alpha) and chemokines (IL-8 and MIP-1alpha) as markers of peri-implant tissue condition. Int J Oral Maxillofac Surg. 2010;39:478-85.

17. Melo RF, Lopes BM, Shibli JA, Marcantonio Junior E, Marcantonio RA, Galli GM. Interleukin-1 $\beta$ and Interleukin-6 Expression and Gene Polymorphisms in Subjects with Peri-Implant Disease. Clin Implant Dent Relat Res. 2012;14:905-14.

18. Liskmann S, Vihalemm T, Salum O, Zilmer K, Fischer K, Zilmer M. Correlations between clinical parameters and interleukin- 6 and interleukin-10 levels in saliva from totally edentulous patients with peri-implant disease. Int J Oral Maxillofac Implants. 2006;21:543-50.

19. Nowzari H, Yi K, Chee W, Rich SK. Immunology, microbiology, and virology following placement of NobelPerfect scalloped dental implants: analysis of a case series. Clin Implant Dent Relat Res. 2008;10:157-65.

20. Page RC, Offenbacher S, Schroeder HE, Seymour GJ, Kornman KS. Advances in the pathogenesis of periodontitis: summary of developments, clinical implications and future directions. Periodontol 2000. 1997;14:216-48.

21. Nares S. The genetic relationship to periodontal disease. Periodontol 2000. 2003:32:36-49.

22. Schwarz F, Sculean A, Rothamel D, Schwenzer K, Georg T, Becker J. Clinical evaluation of an Er: YAG laser for nonsurgical treatment of peri-implantitis: a pilot study. Clin Oral Implants Res. 2005;16:44-52.

23. Nowzari H, Botero JE, DeGiacomo M, Villacres MC, Rich SK. Microbiology and cytokine levels around healthy dental implants and teeth. Clin Implant Dent Relat Res. 2008;10:166-73.

24. Duarte PM, de Mendonça AC, Máximo MB, Santos VR, Bastos MF, Nociti FH. Effect of anti-infective mechanical therapy on clinical parameters and cytokine levels in human peri-implant diseases. J Periodontol. 2009:80:234-43.

25. Mombelli A, Van Oosten MAC, Schürch E, Lang NP. The microbiota associated with succesful or failing osseointegrated titanium implants. Oral Microbiol Immunol. 1987;2:145-51.

26. Giannopoulou C, Bernard JP, Buser D, Carrel A, Belser UC. Effect of intracrevicular restoration margins on peri-implant health: clinical, biochemical, and microbiologic findings around esthetic implants up to 9 years. Int J Oral Maxillofac Implants. 2003;18:173-81.

27. Lang NP, Berglundh T, Working Group 4 of Seventh European Workshop on Periodontology. Periimplant diseases: where are we now? Consensus of the Seventh European workshop on periodontology. J Clin Periodontol. 2011;11:178-81.

28. Luterbacher S, Mayfield L, Brägger U, Lang NP. Diagnostic characteristics of clinical and microbiological tests for monitoring periodontal and peri-implant mucosal tissue conditions during supportive periodontal therapy (SPT). Clin Oral Implants Res. 2000;11:521-9.

29. Kamma JJ, Baehni PC. Five-year maintenance follow-up of early-onset periodontitis patients. J Clin Periodontol. 2003;30:562-72.

30. Mombelli A, Brochut P, Plagnat D, Casagni F, Giannopoulou C. Enamel matrix proteins and systemic antibiotics as adjuncts to non-surgical periodontal treatment: clinical effects. J Clin Periodontol. 2005;32(3):225-30.

31. Lachmann S, Stehberger A, Axmann D, Weber H. The peri-implant health in patients attending an annual recall program. A clinical and microbiological study in 74 patients from the Tübingen Implant Registry. Clin Oral Implants Res. 2013;24:1300-9.

32. Heitz-Mayfield LJ, Lang NP. Comparative biology of chronic and aggressive periodontitis vs. peri-implantitis. Periodontol 2000. 2000;53:167-81.

33. Ata-Ali J, Flichy-Fernandez AJ, Ata-Ali F, Penarrocha-Diago M, Penarrocha-Diago M. Clinical, microbiologic, and host response characteristics in patients with peri-implant mucositis. Int J Oral Maxillofac Implants. 2013;28:883-90.

34. Ata-Ali J, Ata-Ali F, Galindo-Moreno P. Treatment of periimplant mucositis: a systematic review of randomized controlled trials. Implant Dent. 2015;24:13-8. 10.1097/ID.0000000000000190.

35. Quirynen M, De Soete M, van Steenberghe D. Infectious risks for oral implants: a review of the literature. Clin Oral Implants Res. 2002;13:1-19.

36. Roos-Jansåker AM, Lindahl C, Renvert H, Renvert S. Nine- to fourteen-year follow-up of implant treatment. Part I: implant loss and associations to various factors. J Clin Periodontol. 2006;33:283-9.

37. Roos-Jansåker AM, Lindahl C, Renvert H, Renvert S. Nine- to fourteen-year follow-up of implant treatment. Part II: presence of peri-implant lesions. J Clin Periodontol. 2006;33:290-5.

38. Roos-Jansåker AM, Renvert H, Lindahl C, Renvert S. Nine- to fourteen-year follow-up of implant treatment. Part III: factors associated with peri-implant lesions. J Clin Periodontol. 2006:33:296-301.

39. Carcuac O, Jansson L. Peri-implantitis in a specialist clinic of periodontology. Clinical features and risk indicators. Swed Dent J. 2010;34:53-61.

40. Rinke S, Ohl S, Ziebolz D, Lange K, Eickholz P. Prevalence of periimplant disease in partially edentulous patients: a practice-based cross-sectional study. Clin Oral Implants Res. 2011;22:826-33.

41. Marrone A, Lasserre J, Bercy P, Brecx MC. Prevalence and risk factors for peri-implant disease in Belgian adults. Clin Oral Implants Res. 2013;24:934-40.

42. Laugisch O, Schacht M, Guentsch A, Kantyka T, Sroka A, Stennicke HR, et al. Periodontal pathogens affect the level of protease inhibitors in gingival crevicular fluid. Mol Oral Microbiol. 2012;27:45-56.

43. Chen W, Kajiya M, Giro G, Ouhara K, Mackler HE, Mawardi H, et al. Bacteria-derived hydrogen sulfide promotes IL-8 production from epithelial cells. Biochem Biophys Res Commun. 2010;391:645-50.

44. Leonhardt A, Renvert S, Dahlén G. Microbial findings at failing implants. Clin Oral Implants Res. 1999;10:339-45.

45. De Boever AL, De Boever JA. Early colonization of non-submerged dental implants in patients with a history of advanced aggressive periodontitis. Clin Oral Implants Res. 2006;17:8-17.

46. Heuer W, Elter C, Demling A, Neumann A, Suerbaum S, Hannig M, et al. Analysis of early biofilm formation on oral implants in man. J Oral Rehabil. 2007:34:377-82.

47. Emrani J, Chee W, Slots J. Bacterial colonization of oral implants from non-dental sources. Clin Implant Dent Relat Res. 2009;11:106-12.

48. Graves DT, Cochran D. The contribution of interleukin-1 and tumor necrosis factor to periodontal tissue destruction. J Periodontol. 2003;74:391-401.

49. Jandinski JJ, Stashenko P, Feder LS, Leung CC, Peros WJ, Rynar JE, et al. Localization of interleukin-1 beta in human periodontal tissue. J Periodontol. 1991;62:36-43.

50. Stashenko P, Jandinski JJ, Fujiyoshi P, Rynar J, Socransky SS. Tissue levels of bone resorptive cytokines in periodontal disease. J Periodontol. 1991;62:504-9.

51. Ataoglu H, Alptekin NO, Haliloglu S, Gursel M, Ataoglu T, Serpek B, et al. Interleukin-1 beta, tumor necrosis factor-alpha levels and neutrophil elastase activity in peri-implant crevicular fluid. Clin Oral Implants Res. 2002;13:470-6. 
52. Panagakos FS, Aboyoussef $H$, Dondero R, Jandinski JJ. Detection and measurement of inflammatory cytokines in implant crevicular fluid: a pilot study. Int J Oral Maxillofac Implants. 1996;11:794-9.

53. Plagnat D, Giannopoulou C, Carrel A, Bernard JP, Mombelli A, Belser UC Elastase, alpha2-macroglobulin and alkaline phosphatase in crevicular fluid from implants with and without periimplantitis. Clin Oral Implants Res. 2002;13:227-33.

54. Candel-Martí ME, Flichy-Fernández AJ, Alegre-Domingo T, Ata-Ali J, Peñarrocha-Diago MA. Interleukins IL-6, IL-8, IL-10, IL-12 and periimplant disease. An update Med Oral Patol Oral Cir Bucal. 2011;16:e518-21.

55. Pigossi SC, Alvim-Pereira F, Montes CC, Finoti LS, Secolin R, Trevilatto PC, et al. Genetic association study between Interleukin 10 gene and dental implant loss. Arch Oral Biol. 2012;57:1256-63.

56. Defrance T, Vanbervliet B, Briere F, Durand I, Rousset F, Banchereau J. Interleukin 10 and transforming growth factor beta cooperate to induce anti-CD40-activated naive human B cells to secrete immunoglobulin A. J Exp Med. 1992;175(3):671-82.

57. Hajeer AH, Lazarus M, Turner D, Mageed RA, Vencovsky J, Sinnott $P$, et al. IL-10 gene promoter polymorphisms in rheumatoid arthritis. Scand J Rheumatol. 1998;27:142-5.

58. Duarte PM, De Mendonça AC, Máximo MB, Santos VR, Bastos MF, Nociti Júnior FH. Differential cytokine expressions affect the severity of peri-implant disease. Clin Oral Implants Res. 2009;20:514-20.

59. Aboyoussef $\mathrm{H}$, Carter C, Jandinski JJ, Panagakos FS. Detection of prostaglandin E2 and matrix metalloproteinases in implant crevicular fluid. Int J Oral Maxillofac Implants. 1998;13:689-96.

60. Murata M, Tatsumi J, Kato Y, Suda S, Nunokawa Y, Kobayashi Y, et al. Osteocalcin, deoxypyridinoline and interleukin-1 beta in peri-implant crevicular fluid of patients with peri-implantitis. Clin Oral Implants Res. 2002;13:637-43.

61. Havemose-Poulsen A, Sorensen L, Stoltz K, Bendtzen K, Holmstrup P. Cytokine profiles in peripheral blood and whole blood cultures associated with aggressive periodontitis, juvenile idiopathic arthritis and rheumatoid arthritis. J Periodontol. 2005;76:2276-85.

62. Dinarello CA. Proinflammatory cytokines. Chest. 2000;118:503-8.

63. Ejeil AL, Gaultier F, Igondio-Tchen S, Senni K, Pellat B, Godeau G, et al. Are cytokines linked to collagen breakdown during periodontal disease progression? J Periodontol. 2003;74:196-201.

64. Yamazaki K, Nakajima N. Antigen specificity and T cell clonality in periodontal disease. Periodontol 2000. 2004;35:75-100.

65. Baggiolini M, Walz A, Kunkel SL. Neutrophil-activating peptide-1/interleukin 8, a novel cytokine that activates neutrophils. J Clin Invest. 1989:84:1045-9.

66. Deo V, Bhongade ML. Pathogenesis of periodontitis: role of cytokines in host response. Dent Today. 2010;29:60-9.

67. Ejeil AL, Igondjo-Tchen S, Ghomrasseni S, Pellat B, Godeau G, Gogly B. Expression of matrix metalloproteinases (MMPs) and tissue inhibitors of metalloproteinases (TIMPs) in healthy and diseased human gingiva. J Periodontol. 2003;74:188-95.

68. Gamonal J, Acevedo A, Bascones A, Jorge O, Silva A. Levels of interleukin-1 beta, -8 , and -10 and RANTES in gingival crevicular fluid and cell populations in adult periodontitis patients and the effect of periodontal treatment. J Periodontol. 2000;71:1535-45.

69. Hirose M, Ishihara K, Saito A, Nakagawa T, Yamada S, Okuda K. Expression of cytokines and inducible nitric oxide synthase in inflamed gingival tissue. J Periodontol. 2001;72:590-7.

\section{Submit your next manuscript to BioMed Central and take full advantage of:}

- Convenient online submission

- Thorough peer review

- No space constraints or color figure charges

- Immediate publication on acceptance

- Inclusion in PubMed, CAS, Scopus and Google Scholar

- Research which is freely available for redistribution 